\title{
LÀM SẠCH BỀ MẠTT KÍNH NGOÀI CÔNG TRÌNH CÓ SỰ HỖ TRỢ CỦA THIẾT BỊ LAU KÍNH
}

\author{
LÊ MINH SƠN ${ }^{(1)}$, CAO ÁNH DƯƠNG ${ }^{(1)}$ \\ HỒ THANH HOÀNG ${ }^{(2)}$
}

\author{
(1) Khoa Co khi - Điện, Trường Cao đẳng Giao thông vận tải II, \\ ${ }^{2}$ Khoa Công nghệ, Truờng Đại học Công nghiệp thành phố Hồ Chí Minh - Cơ sở Đào tạo Miền Trung; \\ sonlm@caodanggtvt2.edu.vn,duongca@caodanggtvt2.edu.vn, hothanhhoang@iuh.edu.vn
}

Tóm tắt. Hiện nay, hầu hết bề mặt kính công trình cao tầng được làm sạch thủ công. Người thợ phải dùng dây cáp được cố định trên mái công trình và các dụng cụ hỗ trợ để làm sạch bề mặt kính. Đây là công việc ẩn chứa nhiều rủi ro cho người lao động và có hiệu suất làm việc không cao. Vì vậy, việc sử dụng thiết bị thay thế cho người lao động trong việc làm sạch bề mặt kính là rất cần thiết. Thiết bị giúp giảm thiểu rủi ro tai nạn cho người lao động, nâng cao hiệu suất làm sạch và có thể làm việc trong điều kiện trời mưa. Thiết bị được vận hành bởi các cơ cấu hoạt động theo một chu trình xác định trước.

Từ khóa. Thiết bị lau kính

\section{GLASS CLEANING MACHINE AIDED SCAVENGING THE BULDINGS OUTSIDE GLASS SURFACE}

\begin{abstract}
Today, almost the high building glass surface are cleaned by mannual. The labour hang up by the rope which anchor at top of building and they use the support tools to clean the glass surface. This job has many risks for labour and the cleanning capacity is not high. So, using machine substitute labour in cleaning the glass surface is necessary. The machine decrease risks for labour, increase capacity cleaning and do in the rain weather condition. The machine is controlled by the mechanisms which activity follow one before identify cycle.
\end{abstract}

Keywords: Glass cleaning machine

\section{TỔNG QUAN VỀ TİNH HìNH NGHIÊN CÚU VÀ ÚNG DỤNG}

Hiện nay, công trình xây dựng cao ốc, nhà ở và các khu giảng đường cao tầng ngày càng trở nên phổ biến. Công trình giúp tôn lên vẻ đẹp cho thành phố, nhà trường và tạo một diện mạo văn minh hiện đại. Những lợi ích mà công trình cao tầng mang lại là rất lớn.
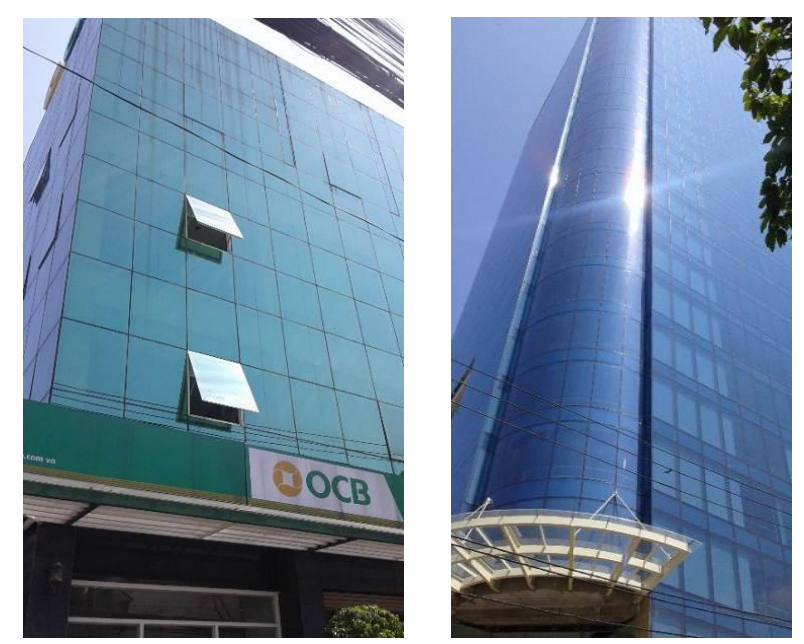

Hình 1. Bề mặt kính hệ mặt dựng không nan nhôm 
Đặc điểm chung bề mặt kính ngoài các công trình cao tầng là diện tích lớn, tạo hình bề mặt thường có dạng phẳng, cong để lấy ánh sáng tự nhiên tối đa. Vì bề mặt tiếp xúc trực tiếp với môi trường và chịu ảnh hưởng trực tiếp bởi nhiều yếu tố dẫn đến làm bẩn bề mặt, bong tróc, hư hỏng bề mặt từ đó dẫn đến hư hỏng kết cấu công trình. Việc làm sạch bề mặt ngoài công trình là rất khó khăn, mất nhiều thời gian, chi phí và rủi ro gây mất an toàn cao. Vì vậy dẫn đến việc bảo dưỡng định kỳ diễn ra không thường xuyên. Kết quả là tuổi thọ công trình giảm và làm giảm thẩm mỹ cho công trình.

Ở Việt Nam hiện nay, thiết bị hỗ trợ cho việc làm sạch bề mặt kính ngoài công trình chỉ dừng lại ở thiết bị nâng hạ giúp người thợ có thể đứng trực tiếp trên thiết bị để lau kính. Và trên thế giới cũng đã có những ứng dụng hỗ trợ cho việc lau kính như robot lau kính, tuy nhiên ứng dụng vào thực tế vẫn chưa rộng rãi, giá thành cao.

Vì vậy, việc thiết kế chế tạo thiết bị làm sạch bề mặt kính ngoài công trình sẽ góp phần giảm thiểu rủi ro tai nạn cho người lao động, tạo nét văn minh hiện đại cho công trình. Phạm vi ứng dụng thiết bị là làm sạch bề mặt ngoài kính cường lực phía ngoài hệ mặt dưng không nan nhôm (Utilized và Spider) ở các công trình.

\section{THIẾT KẾ CHẾ TẠO THIẾT B!}

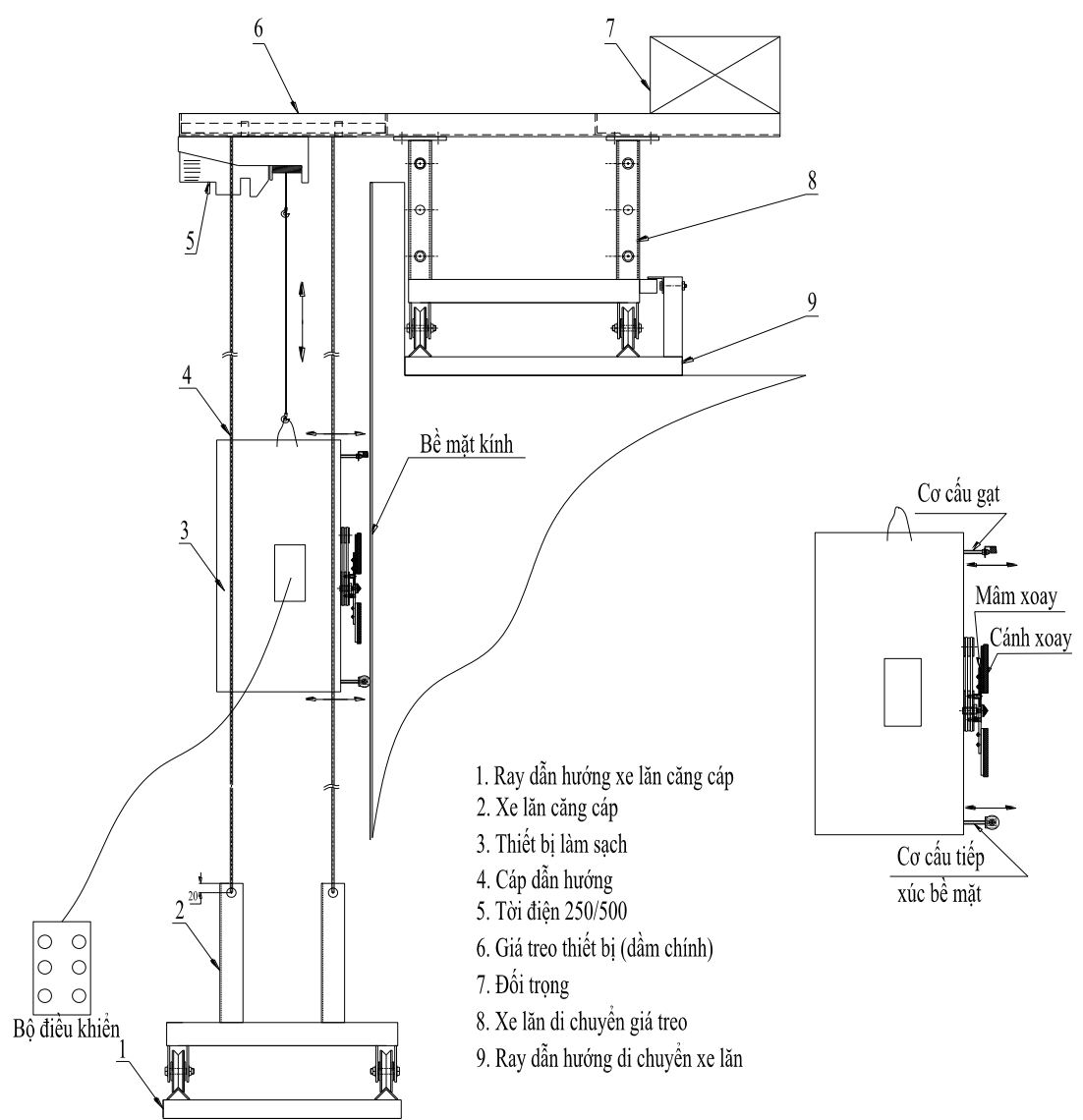

Hình 2. Sơ đồ nguyên lý thiết bị làm sạch bề mặt kính

Thiết bị làm việc theo chu trình như sau: tời điện 5 nâng thiết bị làm sạch 3 lên đến độ cao nhất định, lúc này người điều khiển sẽ tác động các nút điều khiển làm cho cần gạt nước và hai mâm xoay trên thiết bị làm sạch 3 tiếp xúc bề mặt kính, sau đó điều khiển 2 mâm xoay quay ngược chiều nhau đồng thời bật bơm màng tạo áp phun dung dịch lau kính lên bề mặt kính và van điện từ cấp khí nén làm khô bề mặt, tiếp theo điều khiển tời 5 hạ thiết bị làm sạch xuống vị trí xác định. Chu trình lau kết thúc. Tiếp theo, điều chỉnh xe lăn căng cáp 2 và xe lăn di chuyển giá treo đồng thời đến bề mặt kính kế tiếp theo phương ngang với khoảng cách nhỏ hơn bề rộng của hai mâm xoay khoảng $5 \mathrm{~cm}$. Chu trình làm sạch tiếp tục được lặp lại như trên. Trong quá trình thiết bị làm sạch làm viêc, cáp dẫn hướng giúp cho thiết bị ổn định, không bị lắc ngang khi mâm xoay ma sát với bề mặt kính. 
Trong quá trình vận hành, hình ảnh bề mặt làm sạch sẽ được truyền từ camera IP đến máy tính để giám sát và có sự điều chỉnh kịp thời.

Thông số kỹ thuật và công dụng của các cơ cấu trên thiết bị:

- Đối với mâm xoay (hình 3): Để đảm bảo yêu cầu chống ăn mòn, nhẹ, dễ tháo lắp, dễ gia công, độ bền và phù hợp kích thước tấm kính tại công trình. Mâm xoay được làm bằng vật liệu nhôm có đường kính có thể điều chỉnh từ D170 đến D260 thông qua các cánh lắp ghép trên mâm xoay. Mâm xoay được dẫn động bởi bộ truyền đai sử dụng động cơ điện một chiều $24 \mathrm{~V}$ có số vòng quay tối đa 150 vòng/phút. Động cơ điện một chiều đảm bảo khả năng thắng được lực ma sát do lức ép giữa cánh xoay và bề mặt kính. Trên thiết bị bố trí hai mâm xoay nằm ngang quay ngược chiều nhau và được dẫn động bởi hai động cơ điện một chiều.

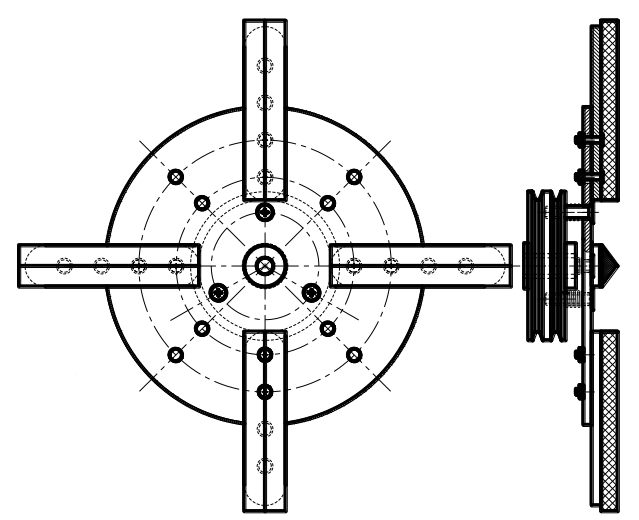

Hình 3. Cơ cấu dẫn động mâm xoay

- Đối với cáp dẫn hướng: Cáp dẫn hướng có vai trò giữ cho thiết bị làm sạch 3 chuyển động theo hướng xác định trước, không bị xoay hay lắc khi mâm xoay tiếp xúc làm sạch bề mặt kính và đảm bảo an toàn trong trường hợp thiết bị rơi tự do. Cáp dẫn hướng được tạo lực căng ban đầu thông qua tăng đơ căng cáp đặt ở hai đầu sợi cáp liên kết với xe lăn 2 và giá treo 8 . Cáp dẫn hướng có chiều dài thay đổi theo chiều cao công trình và đường kính $\mathrm{D} 5$

- Đối với cơ cấu treo thiết bị (hình 4): Cơ cấu treo được làm bằng vật liệu thép, dùng để treo tời điện có tải trọng nâng tối đa $250 \mathrm{Kg}$ và thiết bị làm sạch. Cơ cấu chịu ảnh hưởng trực tiếp tải trọng của thiết bị, tải trọng tời điện, tải trọng bản thân kết cấu thép, tải trọng động khi nâng hạ. Toàn bộ tải trọng tác động lên cơ cấu treo khoảng $40 \mathrm{Kg}$. Tầm vươn của cơ cấu treo ra khỏi bề mặt kính khoảng $60 \mathrm{~cm}$. Cơ cấu treo được liên kết với xe lăn thông qua bulong chịu lực và được cân bằng bởi đối trọng 7 .

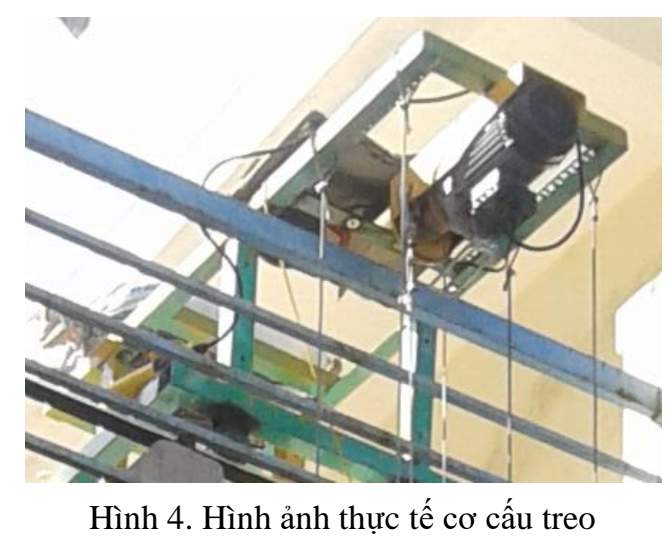

- Đối với hệ thống thủy lực: Hệ thống thủy lực sử dụng nguồn $220 \mathrm{~V}$, gồm bơm màng áp lực 140 Psi $(10 \mathrm{Kg} / \mathrm{cm} 2)$, lưu lượng 1 lít/phút cung cấp dung dịch lau kính thông qua đương ống áp lực đường kính D10 đến 04 đầu phun dạng sương gắn trên thiết bị lau kính. Hệ thống thủy lực làm việc khi hai mâm xoay làm việc. 


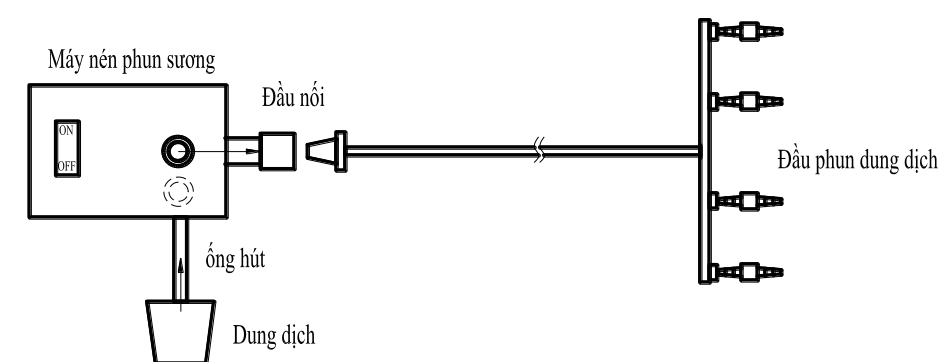

Hình 5. Sơ đồ nguyên lý hệ thống thủy lực

- Đối với hệ thống khí nén (hình 6): Hệ thống khí nén gồm máy nén khí kiểu pittong áp lực $7.5 \mathrm{Kg} / \mathrm{cm} 2$ đấu nối với van điện từ $24 \mathrm{~V}$ kiểu 3 cửa 2 vị trí thông qua ống áp lực mềm D8. Đầu ra của hệ thống khí nén là các đầu xịt tạo khí làm khô bề mặt kính sau khi lau bằng dung dịch. Áp lực khí nén khi làm việc khoẳng từ $4-6 \mathrm{Bar}$

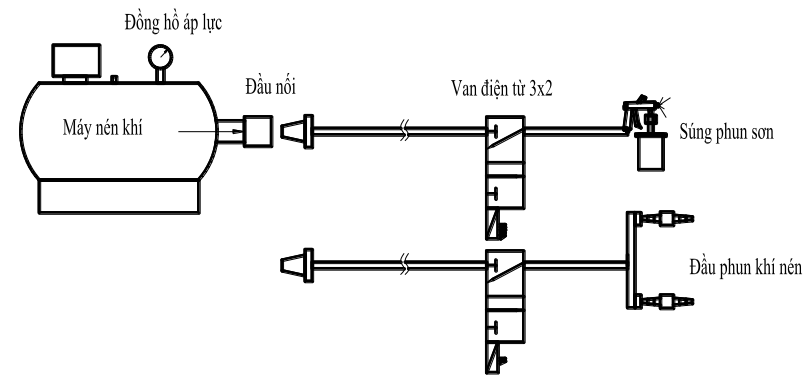

Hình 6. Sơ đồ nguyên lý hệ thống khí nén trên thiêt bị

- Đối với thiết bi điều khiển (hình 7): Để cho người thợ có thể dễ dàng vận hành, bộ điều khiển sử dụng nguồn $15 \mathrm{~A}, 24 \mathrm{~V}$. Trên bộ điều khiển có gắn 10 công tắc 3 trạng thái để đóng mở và đảo chiều quay các động cơ dẫn động cơ cấu công tác trên thiết bị. Và để nhận biết được hành trình làm việc của các cơ cấu điều khiển như: cơ cấu gạt nước, cơ cấu tiếp xúc bề mặt kính trên thiết bị có gắn các công tắc hành trình hiển thị tín hiệu dưới dạng đèn LED.
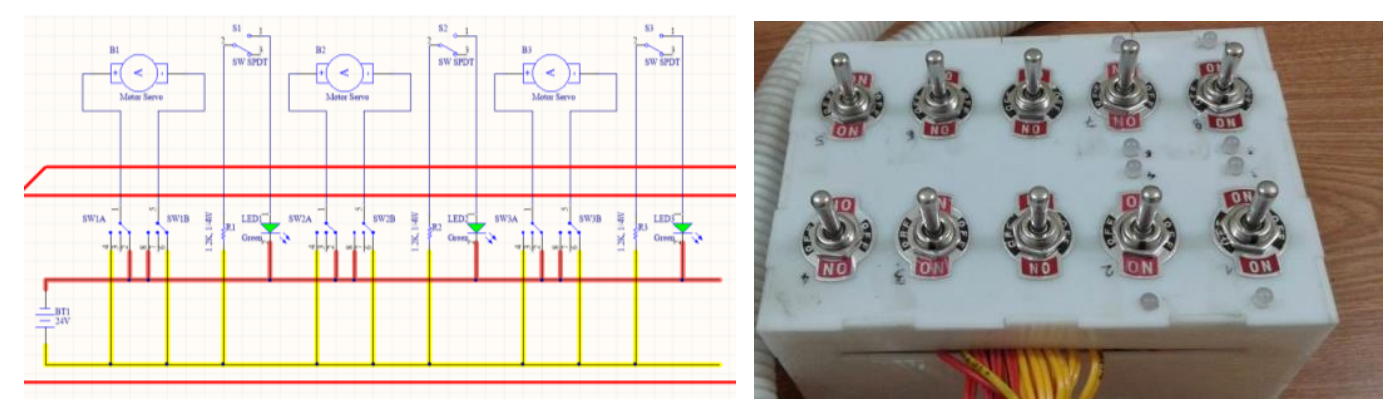

Hình 7. Sơ đồ nguyên lý bảng điều khiển vận hành thiết bị và hình ảnh thực tế

\section{KÊT QUẢ THỰC NGHIỆM}

- Nghiên cứu chế tạo được cơ cấu mâm xoay, cơ cấu dẫn hướng cáp, cơ cấu dẫn hướng tiếp xúc bề mặt, hệ thống điều khiển khí nén, hệ thống điều khiển thủy lực và bộ điều khiển làm việc của các cơ cấu.

- Thiết bị có khả năng làm sạch bề mặt kính, với các thông số như sau: 


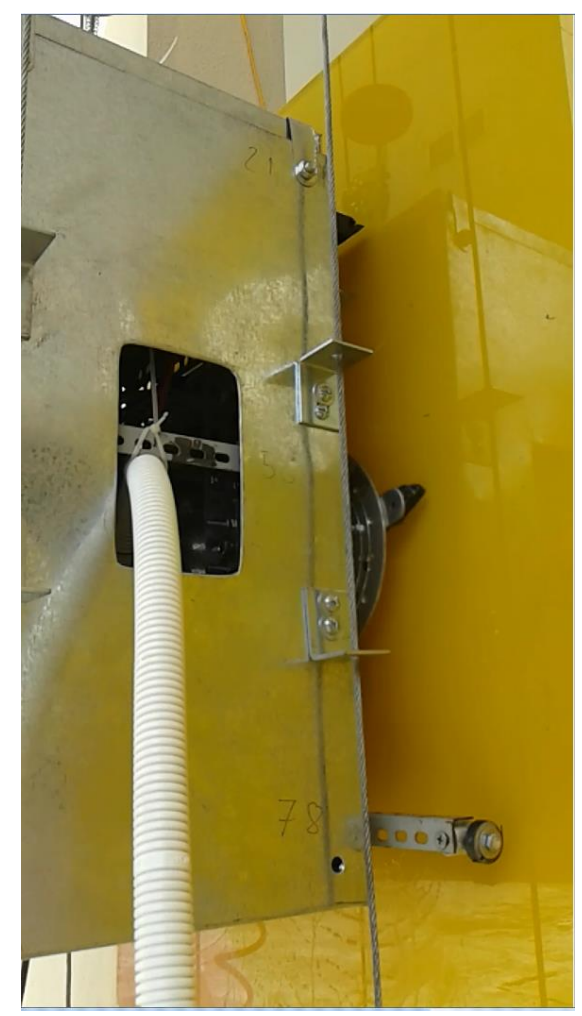

Hình 8. Thiết bị thực tế

+ Bể rộng bề mặt kính làm sạch cho mỗi lần lau: 0,5 mét

+ Tốc độ lau kính:

5 mét/phút

+ Hành trình 1 lần lau tối đa (theo phương đứng): 6 mét

+ Thời gian nghỉ giữa các lần lau: 1 phút

+ Năng suất lau:

+ Chiều cao làm việc tối đa:

+ Điện năng tiêu thụ:

+ Số người vận hành:

$94 \mathrm{~m}^{2} /$ giờ

15 mét

2,5 KWh

03 người ( 01 người bấm nút điều khiển, 01 người giám sát, 01 người điều chỉnh)

\section{KẾT LUẬN}

Thiết bị làm sạch bề mặt kính cường lực hệ mặt dựng không nan nhôm đã thực hiện được công việc thay thế người lao động trong việc lau bề mặt kính ngoài công trình, thiết bị giúp giảm thiểu rủi ro tai nạn cho người lao động trong qua trình làm việc. Năng suất làm việc của thiết bi cao hơn so với lao động thủ công và thiết bị có thể làm việc trong điều kiện trời mưa. Thiết biết bị làm việc ít bị rung lắc, tiếng ồn thấp, tiếp xúc giữa mâm xoay với bề mặt kính đều giúp gạt đi vết bẩn.

Tuy nhiên, bên cạnh đó thiết bị còn có những tồn tại cần cải tiến để có thể thương mại hóa với những hướng phát triển như sau:

- Nâng cao tính tự động trong điều khiển để việc phối hợp chuyển động giữa các cơ cấu nhịp nhàng và hạn chế sai sót do người điều khiển gây ra

- Nghiên cứu cơ cấu bám bề mặt kính để thiết bị có thể linh động hơn trong việc lau bề măt kính và có thể lau được ở những công trình có chiều cao lớn.

\section{TÀI LIỆU THAM KHẢO}

[1] Đỗ Đình Đức (2006), Kỹ thuật thi công, NXB Xây Dựng.

[2] Nguyễn trọng Hiệp (2003), Chi tiết máy 1, NXB Giáo Dục.

[3] Nguyễn Hữu Lộc (2003), Cơ sở thiết kế máy, NXB KHKT. 
[4] Phạm Văn Khảo (1999), Truyền động tự động khí nén, NXB KHKT.

[5] Trần Doãn Đỉnh, Nguyễn Ngọc Lê (1984), Truyền dẫn thủy lực trong chế tạo máy, NXB KHKT.

[6] Trương Quốc Thành (1999), Máy và thiết bi nâng, NXB KHKT

[7] http://www.vietducautomatic.vn/chi-tiet-san-pham/8/he-mat-dung-kinh.html, 20/11/2014

[8] http://technews.tmcnet.com/green/topics/green/articles/2013/04/03/332878-miraikikais-no-water-duster-solarpanel-robot.htm

Ngày nhận bài: 01/04/2017

Ngày chấp nhận đăng: 20/05/2017 